\title{
Antioxidant Activity of Spray-Dried Extracts of Psidium guajava Leaves
}

\author{
Maurette R. V. Fernandes ${ }^{1}$, Luciana M. Kabeya ${ }^{1}$, Cláudia R. F. Souza ${ }^{1}$, Adna P. Massarioli ${ }^{2}$, Severino M. \\ Alencar $^{2} \&$ Wanderley P. Oliveira \\ ${ }^{1}$ Universidade de São Paulo, Faculdade de Ciências Farmacêuticas de Ribeirão Preto, Av. do Café s/n, Ribeirão \\ Preto, SP, 14040-903, Brazil \\ ${ }^{2}$ Universidade de São Paulo, Escola Superior de Agricultura “Luiz de Queiroz”, Av. Pádua Dias, 11, Piracicaba, \\ SP, 13418-900, Brazil \\ Correspondence: Prof. Dr. Wanderley P. Oliveira, Laboratory of R\&D on Pharmaceutical Processes, \\ LAPROFAR, Faculdade de Ciências Farmacêuticas de Ribeirão Preto/USP, Av. do Café s/n, Bloco Q, 14040-903, \\ Ribeirão Preto, SP, Brazil. E-mail: wpoliv@fcfrp.usp.br
}

Received: April 12, 2018

Accepted: May 4, 2018 Online Published: June 14, 2018

doi:10.5539/jfr.v7n4p141

URL: https://doi.org/10.5539/jfr.v7n4p141

\begin{abstract}
Antioxidants from Psidium guajava leaves were extracted with $70 \%$ ethanol in water. The extractive solution was concentrated and submitted to spray drying in the presence of technological adjuvants at a proportion of $8 \%$ wet base. Three distinct technological adjuvants were evaluated: $\beta$-cyclodextrin $(\beta C D-80)$, maltodextrin DE10:Aerosil ${ }^{\circledR}$ (MA-80 - 7:1), and maltodextrin DE10:Encapsia ${ }^{\circledR}:$ Aerosil ${ }^{\circledR}$ (MDEA-80 - 5:2:1). The antioxidant activity of the concentrated extract and spray-dried powders was assessed by three antioxidant assays, namely: the 2,2'-azinobis(3-ethylbenzthiazoline-6-sulfonic acid) (ABTS) radical scavenging, ferric reducing antioxidant power (FRAP), and oxygen radical absorption capacity (ORAC). The 1,1-diphenyl-2-picrylhydrazyl radical (DPPH) scavenging capacity was determined previously. The spray-dried powders exhibited strong antioxidant activity $\left(\mathrm{IC}_{50}\right.$ value $=7.96$ to $9.76 \mu \mathrm{g} / \mathrm{mL}-\mathrm{DPPH}$ method; $3,125.1$ to $3,406.0 \mu \mathrm{M}$ TE/g dry weight - ABTS method; 4,210 to 4,540 $\mu \mathrm{M} \mathrm{FeSO}$ E/g - FRAP method; 1,820-2,020 $\mu \mathrm{M} \mathrm{TE/g} \mathrm{-} \mathrm{ORAC} \mathrm{method).} \mathrm{The}$ technological adjuvants did not significantly interfere with the antioxidant activity of the dried products, regardless the type of antioxidant assay used. The results here reported strongly evidenced that the concentrated and spray-dried extracts of Psidium guajava are rich sources of natural antioxidants with potential application in food, pharmaceutical, and cosmeceutical products.
\end{abstract}

Keywords: antioxidant activity, dried extract, polyphenols, Psidium guajava, spray-drying.

\section{Introduction}

Psidium guajava Linn. (Myrtaceae) is native from Central and South America and has been cultivated in various tropical and subtropical countries. The roots, bark, leaves, and immature fruits of P. guajava are used in many parts of the world for the treatment of wounds and a plethora of diseases, including diabetes, hypertension, and gastroenteritis. The ripe fruits are widely consumed by humans and employed by the food industry to produce juice, jelly, and candies (Gutiérrez, Mitchell, \& Solis, 2008). Extracts of P. guajava, especially from mature leaves, are rich sources of phenolic compounds (Gutiérrez et al., 2008; Venkatachalam, Singh, \& Marar, 2012).

Currently, there is considerable interest in the use of antioxidant compounds from natural sources to preserve and improve the shelf-life of food products, and to increase the stability of fats and meat products (Hygreeva, Pandey, \& Radhakrishna, 2014). A raw herbal material, however, needs to be transformed into a standardized product suitable for industrial use through a multistage process that demands specific processing technologies, including extraction, concentration and drying of bioactive compounds. Standardized dried extracts have several advantages over unprocessed plant material and liquid forms, such as higher physicochemical and microbial stability, easiness in dosage, higher concentration of bioactive compounds, lower transport and storage costs, and capability to be transformed into several dosage forms, such as tablets, granules, and capsules (Oliveira \& Petrovick, 2010).

Spray-drying is a technique commonly used in the pharmaceutical and food industry that is appropriate to dry 
heat-sensitive components such as bioactive compounds present in plant extracts, enzymes, and other pharmaceuticals. Technological carriers such as gums, semi-synthetic cellulose derivatives, and synthetic polymers are commonly added to the drying mixture to protect these components from degradation, optimize the drying performance, and improve the physicochemical properties of the products (Sollohub \& Cal, 2010; Cortés-Rojas \& Oliveira, 2012).

Hydroalcoholic extracts from $P$. guajava leaves are rich in phenolic compounds, flavonoids, and tannins (Venkatachalam et al., 2012; Fernandes et al., 2014a) and may probably act as natural antioxidants for food and pharmaceutical products. Crude and spray-dried extracts from $P$. guajava leaves (PG-SD) exhibit antimicrobial activity against Staphylococcus aureus, Escherichia coli, and Pseudomonas aeruginosa (Fernandes, Dias, Carvalho, Souza, \& Oliveira, 2014b), inhibit the production of oxidant species by human neutrophils (Fernandes et al., 2014a), and scavenge hydrogen peroxide, nitric oxide, and superoxide anion radical (Venkatachalam et al., 2012). The biological activity of the PG-SD extracts resembled that of the initial concentrated extract (Fernandes et al., 2014a).

This study reports the antioxidant activity of crude and spray-dried extracts of $P$. guajava leaves assessed by three distinct in vitro antioxidant methods - 2,2'-azinobis(3-ethylbenzthiazoline-6-sulfonic acid) (ABTS) radical scavenging, ferric reducing antioxidant power (FRAP), and oxygen radical absorption capacity (ORAC) - and compared with the 1,1-diphenyl-2-picrylhydrazyl radical (DPPH) scavenging activity determined previously (Fernandes et al., 2014b). Analysis of the correlation between the antioxidant capacity and the phenolic and flavonoid content of the crude and dried extracts is also presented.

\section{Materials and Methods}

\subsection{Chemicals}

2,2'-azobis(2-amidinopropane) dihydrochloride (AAPH), 2,2'-azinobis(3-ethylbenzthiazoline-6-sulfonic acid) diammonium salt (ABTS), 1,1-diphenyl-2-picrylhydrazyl radical (DPPH), fluorescein sodium salt, gallic acid, and $\operatorname{Trolox}^{\circledR}$ (6-hydroxy-2,5,7,8-tetramethylchroman-2-carboxylic acid) were purchased from Sigma-Aldrich (Steinheim, Germany). Ethanol, $\mathrm{AlCl}_{3}$, phosphomolybdic acid, and sodium tungstate were acquired from Vetec Química Fina (Rio de Janeiro, Brazil). The technological adjuvants colloidal silicon dioxide (Aerosil ${ }^{\circledR} 200$; Evonik Degussa, Hanau, Germany), maltodextrin (MOR-REX 1910; Corn Products of Brazil), $\beta$-cyclodextrin (Roquette; Lestrem, France), and gum arabic (Encapsia ${ }^{\circledR}$; NEXIRA Brazil, São Paulo, SP, Brazil) were obtained from different suppliers.

\subsection{Plant Material}

The leaves of Psidium guajava were collected in 21/02/2011 at "Casa da Goiaba", a farm and food industry

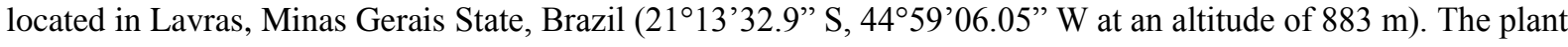
was identified by Prof. Dr. Marcelo Polo and a voucher specimen was deposited at the herbarium of the Federal University of Alfenas (Alfenas, MG, Brazil) under the code UALF-01505.

\subsection{Preparation and Spray-drying of the P. guajava Extract}

The hydroalcoholic extract of $P$. guajava leaves was prepared and dried as reported previously (Fernandes et al., 2014b). Briefly, P. guajava leaves were dried in a circulating air oven (Fanem 315 SE, Guarulhos, Brazil) at $45^{\circ} \mathrm{C}$ until constant weight, ground in a knife mill (MA-680, Marconi Equipamentos para Laboratórios Ltda, Piracicaba, SP - Brazil) until pass through a 20-mesh sieve $(833 \mu \mathrm{m})$. The dried leaves were submitted to dynamic maceration with $70 \%$ ethanol in water $(\mathrm{v} / \mathrm{v})$ at a plant/solvent ratio of 1:10 (w/v), under constant stirring (Nova Ética, model 119, Vargem Grande Paulista, SP, Brazil) for $60 \mathrm{~min}$, at $50{ }^{\circ} \mathrm{C}$. The extractive solution was filtered and concentrated in a rotary evaporator (Fisatom 802, São Paulo, Brazil) at $50{ }^{\circ} \mathrm{C}$ under vacuum, until solid contents reached $12 \%(\mathrm{w} / \mathrm{w})$.

The Psidium. guajava concentrated extract (PG-CE) was mixed with the following technological adjuvants at a proportion of $8 \%$ (wet base): maltodextrin DE10:Aerosil ${ }^{\circledR}$ mixture at 7:1 ratio (MA-80), maltodextrin DE10:Encapsia ${ }^{\circledR}:$ Aerosil $^{\circledR}$ mixtures at a 5:2:1 ratio (MDEA-80), or pure $\beta$-cyclodextrin ( $\beta C D-80$ ). The compositions were dried in a bench-top Lab-Plant SD-05 spray dryer (Lab-Plant UK Ltd., Huddersfield, UK), equipped with a two-fluid atomizer, with an internal orifice of $0.7 \mathrm{~mm}$. The operating parameters were: inlet air drying temperature, $\mathrm{T}_{\mathrm{gi}}=150{ }^{\circ} \mathrm{C}$; drying air flow rate, $\mathrm{W}_{\mathrm{g}}=60 \mathrm{~m}^{3} / \mathrm{h}$; extract feed flow rate, $\mathrm{W}_{\text {susp }}=4 \mathrm{~g} / \mathrm{min}$; atomizing air pressure, $\mathrm{P}_{\mathrm{atm}}=1.5 \mathrm{bar}$ and atomizing air flow rate, $\mathrm{W}_{\mathrm{atm}}=15 \mathrm{lpm}$. 


\subsection{Determination of Antioxidant Activity}

\subsubsection{DPPH Assay}

The DPPH assay was performed as reported previously (Fernandes et al., 2014b). The results were expressed as $\mathrm{IC}_{50}$, which represents the sample concentration in $\mu \mathrm{g} / \mathrm{mL}$ required to reduce $50 \%$ of the DPPH free radicals added to the reaction medium. All the measurements were performed in triplicate.

\subsubsection{ABTS Assay}

This study used the ABTS radical cation $\left(\mathrm{ABTS}^{\circ+}\right.$ ) decolorization assay protocol reported by Re et al. (1999), with slight modifications. A stock solution of $\mathrm{ABTS}^{\text {*+ }}$ was prepared by mixing ABTS solution with $\mathrm{K}_{2} \mathrm{~S}_{2} \mathrm{O}_{8}$ solution (final concentrations of $7 \mathrm{mM}$ and $140 \mathrm{mM}$, respectively). The mixture was maintained in the dark at room temperature for $16 \mathrm{~h}$ before use. To obtain the working $\mathrm{ABTS}^{\circ+}$ solution, the stock solution was diluted in absolute ethanol to achieve an absorbance value of $0.7( \pm 0.05)$ at $\lambda=734 \mathrm{~nm}$, recorded in the UV/vis HP 8453 spectrophotometer (Agilent Technologies, Waldbronn - Germany).

The test-samples $(10 \mu \mathrm{L})$, ethanol (control), or Trolox ${ }^{\circledR}$ were added to the $\mathrm{ABTS}^{\circ+}$ working solution $(3 \mathrm{~mL})$ and, after a 6-min incubation at room temperature, in the dark, the absorbance was recorded at $734 \mathrm{~nm}$. An equivalent volume of ethanol was set as blank. The percentage of absorbance decrease promoted by each sample was interpolated into the standard curve built with $\operatorname{Trolox}^{\circledR}(0-2000 \mu \mathrm{M})$ to calculate their concentration in Trolox ${ }^{\circledR}$ equivalents $(\mu \mathrm{M} \mathrm{TE})$. Each sample was analyzed in triplicate.

\subsubsection{FRAP Assay}

This study used a modified version of the FRAP assay reported by Benzie and Strain (1996). The working FRAP reagent was prepared daily by mixing $0.3 \mathrm{M}$ acetate buffer $\mathrm{pH} 3.6,10 \mathrm{mM}$ 2,4,6-tri(2-pyridyl)-s-triazine (prepared in $40 \mathrm{mM} \mathrm{HCl}$ ), and $20 \mathrm{mM} \mathrm{FeCl}{ }_{3}$ at a proportion of 10:1:1. The test-samples $(90 \mu \mathrm{L})$ and deionized water $(270 \mu \mathrm{L})$ were added to freshly prepared FRAP reagent $(2.7 \mathrm{~mL})$. After a 30 -min incubation at $37^{\circ} \mathrm{C}$ in a water bath (Fisaton 550, São Paulo, Brazil) the absorbance of the reaction mixture was recorded at $595 \mathrm{~nm}$ in the UV/vis HP 8453 spectrophotometer (Agilent Technologies, Waldbronn - Germany), using the FRAP reagent as blank. The ferric reducing capacity of the test-samples was calculated by interpolating the absorbance values in the standard curve built with $\mathrm{FeSO}_{4}(250-1500 \mu \mathrm{M})$, and expressed as $\mu \mathrm{M} \mathrm{Fe}^{2+} / \mathrm{g}$ of sample. The assay was performed in triplicate.

\subsubsection{ORAC Assay}

The ORAC assay was carried out according to the procedure described by Melo et al. (2015), with some modifications. Briefly, the test-samples $(30 \mu \mathrm{L})$ were mixed with fluorescein $(60 \mu \mathrm{L}$ of a $508 \mathrm{nM}$ solution prepared in $75 \mathrm{mM}$ phosphate buffer $\mathrm{pH}$ 7.4) in 96-well dark plates. The reaction was started by adding AAPH $(110 \mu \mathrm{L} ; 76 \mathrm{mM})$ and the fluorescence was recorded immediately and every 1 min thereafter for 120 or $160 \mathrm{~min}$, at $37^{\circ} \mathrm{C}$, at excitation and emission wavelengths of 485 and $528 \mathrm{~nm}$, respectively, using an automated microplate reader (Molecular Devices SpectraMax M3, San Jose, California, EUA). Trolox ${ }^{\circledR}(12.5-400 \mu \mathrm{M})$ was used to prepare the standard curve. All the samples were analyzed in triplicate.

The area under the curve (AUC) was calculated for each sample by integrating the relative fluorescence curve. The net AUC of the sample was calculated by subtracting the AUC of the blank. The regression equation between net AUC and concentration of Trolox ${ }^{\circledR}$ was used to express the antioxidant activity of the test-samples as $\mu \mathrm{M} \mathrm{TE/g} \mathrm{dry} \mathrm{weight.}$

\subsection{Statistical Analysis}

Statistical analysis was performed using the SAS/STAT ${ }^{\circledR}$ software version 9.0 (SAS Institute, Cary, NC, USA, 2002). Statistical differences between groups were analyzed using the Kruskall-Wallis test followed by the Dunn's test. $\mathrm{IC}_{50}$ values were calculated by non-linear regression analysis from the concentration-response inhibition curve. The Pearson's correlation coefficient $(r)$ was calculated to analyze the correlation between antioxidant capacity assessed using different methods and the content of flavonoids and phenolic compounds.

\section{Results and Discussion}

The concentrated and spray-dried extracts from P. guajava leaves are rich in phenolic compounds (Fernandes et al., 2014; Fernandes et al., 2014b). The total flavonoid and polyphenol content of the concentrated and spray-dried extracts MA-80, MDEA- 80 and $\beta C D-80$ are respectively (Fernandes et al., 2014b): $22.58 \pm 0.08$ $(\mathrm{mg} / \mathrm{g}, \mathrm{db})$ and $23.21 \pm 0.72(\% \mathrm{~m} / \mathrm{m}, \mathrm{db}), 13.35 \pm 0.32(\mathrm{mg} / \mathrm{g}, \mathrm{db})$ and $10.52 \pm 0.35(\% \mathrm{~m} / \mathrm{m}, \mathrm{db}), 15.48 \pm 0.87$ $(\mathrm{mg} / \mathrm{g}, \mathrm{db})$ and $9.67 \pm 0.10(\% \mathrm{~m} / \mathrm{m}, \mathrm{db}), 12.58 \pm 0.17(\mathrm{mg} / \mathrm{g}, \mathrm{db})$ and $12.47 \pm 0.66(\% \mathrm{~m} / \mathrm{m}, \mathrm{db})$. Polyphenol content was expressed in terms of gallic acid equivalents, while total flavonoid content was expressed in 
milligrams of quercetin per gram of extract (dry base, $d b$ ).

Several studies have associated the content of polyphenols with the antioxidant activity of herbal extracts. The redox properties of these compounds enable them to act as reducing agents, hydrogen donors, singlet oxygen quenchers, metal chelators, and reductants of ferryl hemoglobin (Cíz et al., 2010; Gebicka \& Banasiak, 2009). There is not an elementary comprehensive method to accurately estimate and quantify the antioxidant activity, because oxidative processes involve multiple active species, reaction characteristics, and mechanisms (Niki, 2010). Hence, the literature recommends the use of methods with different mechanisms of oxidation inhibition to examine the antioxidant capacity of a given sample (Alañón, Castro-Vázquez, Díaz-Maroto, Gordon, \& Pérez-Coello, 2011). The present study used the $\mathrm{ABTS}^{\circ+}$ radical scavenging, FRAP, and ORAC assays to analyze the antioxidant activity of concentrated and spray-dried extracts of $P$. guajava leaves (Table 1).

The ABTS assay principle is based on the ability of a given compound to quench ABTS $^{\circ+}$ relatively to Trolox ${ }^{\circledR}$, which is a hydrophilic analogue of vitamin $\mathrm{E}$ used as reference antioxidant. The ability of a given compound to reduce a ferric complex ( $\mathrm{Fe}^{3+}$-tripyridyltriazine) to a ferrous complex ( $\mathrm{Fe}^{2+}$-tripyridyltriazine), at low $\mathrm{pH}$, is the basic principle of the FRAP assay. The ORAC method is based on the thermal decomposition of AAPH to generate free radicals, mainly peroxyl radicals, which react with fluorescein and change its fluorescence emission profile (Floegel, Kim, Chung, Koo, \& Chun, 2011). It must be emphasized that the ORAC assay combines both the inhibition time and the degree of inhibition by the antioxidant into a single quantity. It ensures that, at the end of the process, all the antioxidants present in the sample have reacted with the free radicals generated. Compared with the ABTS and FRAP assays, the ORAC method requires a more expensive equipment and longer assay time (Zulueta, Esteve, \& Frígola, 2009; Dudonné, Vitrac, Coutière, Woillez, \& Mérillon, 2009).

Table 1. Antioxidant activity of the concentrated and spray-dried extracts from P. guajava leaves.

\begin{tabular}{llll}
\hline Sample & ABTS $(\boldsymbol{\mu M}$ TE/g) & FRAP $(\boldsymbol{\mu M}$ FeSO4 E/g) & ORAC $(\boldsymbol{\mu M}$ TE/g) \\
\hline PG-SD/MA-80 & $3,125.13(173.44)$ & $4,310(330)$ & $1,820(20)$ \\
PG-SD/MDEA-80 & $3,406.00(113.68)$ & $4,210(190)$ & $1,900(40)$ \\
PG-SD/BCD-80 & $3,357.99(301.50)$ & $4,540(190)$ & $2,020(120)$ \\
PG-CE & $3,392.69(84.61)$ & $8,947(180)$ & $1,330(90)$ \\
\hline
\end{tabular}

Data are expressed as the mean (standard deviation) of triplicate measurements. PG-CE: concentrated extract. PG-SD: spray-dried extract with the technological adjuvants MA-80 (maltodextrin DE10:Aerosil ${ }^{\circledR}$ ), MDEA-80 (maltodextrin DE10:Encapsia ${ }^{\circledR}:$ Aerosi $^{\circledR}$ ), or $\beta C D-80$ ( $\beta$-cyclodextrin). TE: Trolox ${ }^{\circledR}$ equivalents.

The antioxidant activity of $P$. guajava concentrated extract (PG-CE) and of the spray-dried products (PG-SD/MA-80, PG-SD/MDEA-80, and PG-SD/BCD-80) were similar to each other, and ranged from 3,125.1 to $3,406.0 \mu \mathrm{M} \mathrm{TE} / \mathrm{g}$ dry weight, when assessed by the ABTS assay (Table 1). These results corroborate literature reports on the powerful antioxidant capacity of different $P$. guajava leaf extracts determined by this assay (Nantitanon, Yotsawimonwat, \& Okonogi, 2010). The antioxidant activity of the P. guajava samples tested herein were (i) sixfold stronger than that exhibited by Bidens pilosa extracts spray-dried with Aerosil ${ }^{\circledR}$ as adjuvant, which ranged from 421 to $527 \mu \mathrm{M}$ TE/g dry weight (Cortés-Rojas \& Oliveira, 2012); and (ii) more effective than that displayed by 27 plants used in Peruvian folk medicine, which ranged from 3.7 to $1,045.3 \mu \mathrm{M}$ TE/g dry weight (Chirinos, Pedreschi, Rogez, Larondelle, \& Campos, 2013).

Considering that the antioxidant activity of phenolic compounds usually correlates with their reducing capacity, the FRAP assay represents a reliable and reproducible method to analyze the antioxidant activity of various compounds (Benzie \& Strain, 1996; Pérez-Jiménez et al., 2008). The three Psidium. guajava spray-dried extracts (PG-SD: MA-80, MDEA-80, and $\beta C D-80$ ) exhibited similar reducing effects, which were twofold weaker than that exerted by PG-CE $\left(8,947 \mu \mathrm{M} \mathrm{FeSO}_{4} \mathrm{E} / \mathrm{g}\right)$, as evaluated by the FRAP assay (Table 1). These findings are in line with a previous report on the twofold stronger antioxidant activity of PG-CE (mean $\mathrm{IC}_{50}$ value $=3.34$ $\mu \mathrm{g} / \mathrm{mL}$ ), as compared with the antioxidant activity of PG-SD (mean $\mathrm{IC}_{50}$ value $=7.96-9.76 \mu \mathrm{g} / \mathrm{mL}$ ) assessed by the DPPH method, which measures the hydrogen donating capacity of a given compound (Fernandes et al., 2014b). It was hypothesized that the drying adjuvants diluted the antioxidant compounds of PG-CE, because the concentration of total phenolic compounds and total flavonoids in the three PG-SD were nearly twofold lower than the ones detected in PG-CE (Fernandes et al., 2014b).

The standard antioxidants ascorbic acid, butylated hydroxyanisole (BHA), and butylated hydroxytoluene (BHT) yielded $\mathrm{IC}_{50}$ values of $2.96 \pm 0.15,2.97 \pm 0.32$, and $12.52 \pm 0.25 \mu \mathrm{g} / \mathrm{mL}$, respectively, when assayed using the DPPH method. Therefore, PG-CE was as effective as ascorbic acid and BHA, while PG-SD was more effective than 
BHT in donating hydrogen to the DPPH radical. It indicates that the antioxidant efficiency of the concentrated and spray-dried extracts of $P$. guajava was similar to that exhibited by commercial synthetic antioxidant compounds. Compared with synthetic single dietary antioxidants, natural antioxidants from herbal products may be more effective due to the synergistic action among their components (Pérez-Jiménez et al., 2008).

The absolute values of $\mu \mathrm{M} \mathrm{TE} / \mathrm{g}$ obtained using the ORAC method were lower than those obtained using the ABTS assay (Table 1), for the concentrated and spray-dried P. guajava extracts. The antioxidant activity of the PG-SD samples, as determined by the ORAC assay $(1,820-2,020 \mu \mathrm{M} \mathrm{TE} / \mathrm{g})$, were comparable to that of açaí berry juice (Euterpe oleraceae Mart.) spray-dried with maltodextrin $10 \mathrm{DE}(2,376.29 \mu \mathrm{M} \mathrm{TE} / \mathrm{g})$ and Arabic gum $(2,408.87 \mu \mathrm{M} \mathrm{TE} / \mathrm{g})$ (Silva et al., 2014). Açaí berries are commonly consumed in human diet due to their high concentration of antioxidant compounds. Compared with PG-SD, Myrciaria cauliflora extracts spray-dried with arabic gum and maltodextrin exhibited weaker antioxidant effect (737-900 $\mu \mathrm{M} \mathrm{TE} / \mathrm{g})$, as assessed by the ORAC assay (Tonon, Brabet, Pallet, Brat, \& Hubinger, 2009). Using this method, the antioxidant activity of $P$. guajava fruit methanol extract was $21.3 \mu \mathrm{M} \mathrm{TE} / \mathrm{g}$ fresh mass (Thaipong, Boonprakob, Crosby, Cisneros-Zevallos, \& Byrne, 2006), which was nearly sixtyfold weaker than that exerted by the PG-CE leaf extract $(1,330 \mu \mathrm{M} \mathrm{TE} / \mathrm{g})$ (Table 1).

The PG-SD prepared with different technological adjuvants (MA-80, MDEA-80, and $\beta C D-80$ ) exhibited similar antioxidant activity, regardless the antioxidant assay type. This finding indicates that the type of adjuvant used herein did not significantly interfere with the antioxidant capacity of the dried product. Maltodextrin and cyclodextrins lack functional groups able to donate electrons or hydrogen to free radicals (Phillips, Carlsen, \& Blomhoff, 2009; Jullian, Moyano, Yañez, \& Olea-Azar, 2007), but Arabic gum has a little protein content, which could exert a weak antioxidant effect mediated by the amino acids tyrosine, histidine, and methionine (Fazaeli, Emam-Djomeh, Ashtari, \& Omid, 2012). However, in this study the PG-SD samples with and without Arabic gum (MDEA-80 and MA-80, respectively) exhibited similar antioxidant activity.

It has been previously reported that the total amount of phenolic compounds and flavonoids does not significantly vary across the $P$. guajava spray-dried extracts due to addition of technological adjuvants (Fernandes et al., 2014b). The Pearson's correlation coefficient between the antioxidant capacity of PG-SD assessed by different methods and their content of total phenols and flavonoids was determined, and the results are presented in Table 2. According to the absolute values of $r$, the correlation can be classified as: Negligible (0.00 to 0.30$)$, Low (0.30-0.50), Moderate (0.50-0.70), High (0.70-0.90), Very high (0.90-1.00), being 1.00 a perfect correlation. Values lower or higher than 0.0 imply negative or positive correlations, respectively (Mukaka, 2012). Experimental data of the percentage of maximum DPPH free radical scavenging (DPPH_\%), concentration of the sample that scavenges $50 \%$ of the DPPH free radical added to the reaction medium $\left(\mathrm{DPPH}_{-} \mathrm{IC}_{50}\right)$, total flavonoids (TF), and total polyphenols (TP) have been reported so far (Fernandes et al., 2014b).

Table 2. Pearson's correlation coefficient between antioxidant activity of $P$. guajava spray-dried extracts assessed by different methods and their total phenol and flavonoid content.

\begin{tabular}{|c|c|c|c|c|c|c|c|}
\hline & ABTS & DPPH_\% & DPPH_IC50 & FRAP & TF & ORAC & TP \\
\hline ABTS & - & -0.149 & -0.019 & -0.181 & 0.065 & -0.210 & 0.062 \\
\hline DPPH_\% & & - & -0.682 & 0.364 & 0.667 & 0.192 & 0.580 \\
\hline DPPH_IC50 & & & - & -0.244 & -0.976 & -0.071 & -0.980 \\
\hline FRAP & & & & - & 0.290 & 0.965 & 0.286 \\
\hline $\mathrm{TF}$ & & & & & - & 0.128 & 0.947 \\
\hline ORAC & & & & & & - & 0.124 \\
\hline
\end{tabular}

The percentage of DPPH radical scavenging positively correlated with the concentration of total flavonoids $(r=$ $0.667)$ and phenolic compounds $(r=0.580)$. As expected, the $\mathrm{IC}_{50}$ values for the $\mathrm{DPPH}$ radical scavenging $\left(\mathrm{DPPH} \_\mathrm{IC}_{50}\right)$ negatively correlated with the content of flavonoids $(r=-0.976)$ and phenolic compounds $(r=$ $-0.980)$, and with the percentage of DPPH radical scavenging (DPPH_\%) $(r=-0.682)$. These results corroborate literature reports on the strong positive correlation between the concentration of these compounds and the DPPH radical scavenging capacity, as determined using the Spearman's-Rho coefficient and other correlation parameters; the $r$ values reported ranged from 0.708 to 0.939 (Floegel et al., 2011; Dudonné et al., 2009).

Concerning the methods used to examine the antioxidant capacity of PG-SD, data from the DPPH radical scavenging assay only weakly correlated with data from the FRAP and ORAC methods $(r=0.364$ and 0.192 , 
respectively). In contrast, there was a strong positive correlation between the antioxidant activity of PG-SD assessed by the FRAP and ORAC methods $(r=0.965)$. Data from these assays correlate moderately in studies of the antioxidant activity of serum (Cao \& Prior, 1998), aqueous extracts of 30 plants $(r=0.618)$ (Dudonné et al., 2009), and oak wood used in wine ageing $(r=0.730)$ (Alañón et al., 2011). In a study comprising 927 freeze-dried vegetable samples, the results from FRAP and ORAC assays did not correlate well, probably due to the huge variability in chemical composition and reactivity rate among the samples (Ou, Huang, Hampsch-Woodill, Flanagan, \& Deemer, 2002). ORAC is considered as the most sensitive method to measure chain-breaking antioxidant function, which involves the hydrogen atom transfer pathway (Cíz et al., 2010).

The total amount of phenolic compounds strongly and positively correlated with the total flavonoid content $(r=$ 0.947), which indicates that flavonoids are the major phenolic compounds that account for the overall antioxidant effect of $P$. guajava extracts. These results agree with literature reports on the marked contribution of phenolic compounds to the antioxidant activity of $P$. guajava leaf extracts (Venkatachalam et al., 2012; Nantitanon et al., 2010). The expressive contribution of phenolic compounds to the antioxidant activity assessed by different methods underscores their multiple mechanisms of action, such as quenching of reactive oxygen species, free radical scavenging, reducing power, and reduction of peroxyl radicals (Cíz et al., 2010).

Considering the high complexity of composition of herbal extracts, the isolation and study of individual antioxidant compounds would be ineffective without understanding the synergistic and/or antagonistic interactions among them within a given matrix (Müller, Fröhlich, \& Böhm, 2011). The experimental results reported herein strongly evidences that the $P$. guajava leaf extract is a good source of phenolic compounds, whose total amount and antioxidant activity are preserved after spray-drying with different technological adjuvants (Fernandes et al., 2014b). These features, associated with the fact that the three PG-SD fit the United States Pharmacopoeia recommendations with respect to the product moisture content, water activity, water solubility, and particle size (Fernandes et al., 2014a) make PG-SD promising raw materials to be used as natural antioxidants in food, cosmetic, and pharmaceutical products. Further studies are undertaken to develop practical applications for the products.

\section{Conclusions}

This study demonstrated the feasibility of spray drying for the production of standardized $P$. guajava leaf extracts that are rich in phenolic compounds and exhibit marked antioxidant capacity. The antioxidant capacity of the products has been confirmed through four in vitro assays based on different chemical principles, namely 1,1-diphenyl-2-picrylhydrazyl radical (DPPH) scavenging activity, 2,2'-azinobis (3-ethylbenzthiazoline-6-sulfonic acid) (ABTS) radical scavenging, ferric reducing antioxidant power (FRAP), and oxygen radical absorption capacity (ORAC). The strong antioxidant capacity and the physicochemical properties of the spray-dried P. guajava extracts demonstrate their potential to be used as natural antioxidants in food, pharmaceutical, and cosmeceutical products.

\section{Acknowledgements}

The authors thank the Brazilian funding agencies CNPq (Conselho Nacional de Desenvolvimento Científico e Tecnológico - grant 140951/2010-5) and FAPESP (Fundação de Apoio à Pesquisa do Estado de São Paulo grants 2011/10333-1 and 2014/15905-1) for the financial support.

\section{References}

Alañón, M. E., Castro-Vázquez, L., Díaz-Maroto, M. C., Gordon, M. H., \& Pérez-Coello, M. S. (2011). A study of the antioxidant capacity of oak wood used in wine ageing and the correlation with polyphenol composition. Food Chemistry, 128, 997-1002. https://doi.org/10.1016/j.foodchem.2011.04.005

Benzie, I. F. F., \& Strain, J. J. (1996). The ferric reducing ability of plasma (FRAP) as a measure of antioxidant power: the FRAP assay. Analytical Biochemistry, 239, 70-76. https://doi.org/10.1006/abio.1996.0292

Cao, G. H., \& Prior, R. L. (1998). Comparison of different analytical methods for assessing total antioxidant capacity of human serum. Clinical Chemistry, 44, 1309-1315. Retrieved from http://clinchem.aaccjnls.org/content/clinchem/44/6/1309.full.pdf

Chirinos, R., Pedreschi, R., Rogez, H., Larondelle, Y., \& Campos, D. (2013). Phenolic compound contents and antioxidant activity in plants with nutritional and/or medicinal properties from the Peruvian Andean region. Industrial Crops and Products, 47, 145-152. https://doi.org/10.1016/j.indcrop.2013.02.025

Cíz, M., Cizova, H., Denev, P., Kratchanova, M., Slavov, A., \& Lojek, A. (2010). Different methods for control and comparison of the antioxidant properties of vegetables. Food Control, 21, 518-523. 
https://doi.org/10.1016/j.foodcont.2009.07.017

Cortés-Rojas, D. F., \& Oliveira, W. P. (2012). Physicochemical properties of phytopharmaceutical preparations as affected by drying methods and carriers. Drying Technology, 30, 921-934. https://doi.org/10.1080/07373937.2012.666608

Dudonné, S., Vitrac, X., Coutière, P., Woillez, M., \& Mérillon, J. M. (2009). Comparative study of antioxidant properties and total phenolic content of 30 plant extracts of industrial interest using DPPH, ABTS, FRAP, SOD, and ORAC Assays. Journal of Agricultural and Food Chemistry, 57, 1768-1774.

Fazaeli, M., Emam-Djomeh, Z., Ashtari, A. K., \& Omid, M. (2012). Effect of spray drying conditions and feed composition on the physical properties of black mulberry juice powder. Food and Bioproducts Processing, 90, 667-675. https://doi.org/10.1016/j.fbp.2012.04.006

Fernandes, M. R. V., Azzolini, A. E. C. S., Martinez, M. L. L., Souza, C. R. F., Lucisano-Valim, Y. M., \& Oliveira, W. P. (2014a). Assessment of antioxidant activity of spray dried extracts of Psidium guajava leaves by DPPH and chemiluminescence inhibition in human neutrophils. BioMed Research International. http://dx.doi.org/10.1155/2014/382891

Fernandes, M. R. V., Dias, A. L. T., Carvalho, R. R., Souza, C. R. F., \& Oliveira, W. P. (2014b). Antioxidant and antimicrobial activities of Psidium guajava L. spray-dried extracts. Industrial Crops and Products, 60, 39-44. https://doi.org/10.1016/j.indcrop.2014.05.049

Floegel, A., Kim, D. O., Chung, S. J., Koo, S. I., \& Chun, O. K. (2011). Comparison of ABTS/DPPH assays to measure antioxidant capacity in popular antioxidant-rich US foods. Journal of Food Composition and Analysis, 24, 1043-1048. https://doi.org/10.1016/j.jfca.2011.01.008

Gebicka, L., \& Banasiak, E. (2009). Flavonoids as reductants of ferryl hemoglobin. Acta Biochimica Polonica, 56, 509-513. Retrieved from http://www.actabp.pl/pdf/3_2009/509.pdf

Gutiérrez, R. M. P., Mitchell, S., \& Solis, R. V. (2008). Psidium guajava: a review of its traditional uses, phytochemistry and pharmacology. Journal of Ethnopharmacology, 117, 1-27. https://doi.org/10.1016/j.jep.2008.01.025

Hygreeva, D., Pandey, M. C., \& Radhakrishna, K. (2014). Potential applications of plant based derivatives as fat replacers, antioxidants and antimicrobials in fresh and processed meat products. Meat Science, 98, 47-57. https://doi.org/10.1016/j.meatsci.2014.04.006

Jullian, C., Moyano, L., Yañez, C., \& Olea-Azar, C. (2007). Complexation of quercetin with three kinds of cyclodextrins: an antioxidant study. Spectrochimica Acta Part A: Molecular and Biomolecular Spectroscopy, 67, 230-234. https://doi.org/10.1016/j.saa.2006.07.006

Melo, P. S., Massarioli, A. P., Denny, C., dos Santos, L. F., Franchin, M., Pereira, G. E., Souza, T. M. F. de S., Rosalen, P. L., \& de Alencar, S. M. (2015). Winery by-products: extraction optimization, phenolic composition and cytotoxic evaluation to act as a new source of scavenging of reactive oxygen species. Food Chemistry, 181, 160-169. https://doi.org/10.1016/j.foodchem.2015.02.087

Mukaka, M. M. (2012). Statistics corner: A guide to appropriate use of correlation coefficient in medical research. Malawi Medical Journal, 24(3), 69-71. https://www.ncbi.nlm.nih.gov/pmc/articles/PMC3576830/

Müller, L., Fröhlich, K., \& Böhm, V. (2011). Comparative antioxidant activities of carotenoids measured by ferric reducing antioxidant power (FRAP), ABTS bleaching assay (TEAC), DPPH assay and peroxyl radical scavenging assay. Food Chemistry, 129, 139-148. https://doi.org/10.1016/j.foodchem.2011.04.045

Nantitanon, W., Yotsawimonwat, S., \& Okonogi, S. (2010). Factors influencing antioxidant activities and total phenolic content of guava leaf extract. LWT - Food Science and Technology, 43, 1095-1103. https://doi.org/10.1016/j.lwt.2010.02.015

Niki, E. (2010). Assessment of antioxidant capacity in vitro and in vivo. Free Radical Biology \& Medicine, 49, 503-515. https://doi.org/10.1016/j.freeradbiomed.2010.04.016

Oliveira, O. W., \& Petrovick, P. R. (2010). Secagem por aspersão (spray drying) de extratos vegetais: bases e aplicações. Revista Brasileira de Farmacognosia, 641-650. http://dx.doi.org/10.1590/S0102-695X2010000400026

Ou, B. X., Huang, D. J., Hampsch-Woodill, M., Flanagan, J. A., \& Deemer, E. K. (2002). Analysis of antioxidant activities of common vegetables employing oxygen radical absorbance capacity (ORAC) and ferric reducing antioxidant power (FRAP) assays: a comparative study. Journal of Agricultural and Food 
Chemistry, 50, 3122-3128. https://pubs.acs.org/doi/abs/10.1021/jf0116606

Pérez-Jiménez, J., Aranz, S., Tabernero, M., Díaz-Rubio, M. E., Serrano, J., Goňi, I., \& Saura-Calixto, F. (2008). Updated methodology to determine antioxidant capacity in plant foods, oils and beverages: extraction, measurement and expression of results. Food Research International, 41, 274-285. https://doi.org/10.1016/j.foodres.2007.12.004

Phillips, K. M., Carlsen, M. H., \& Blomhoff, R. (2009). Total antioxidant content of alternatives to refined sugar. Journal of the American Dietetic Association, 109, 64-71. https://doi.org/10.1016/j.jada.2008.10.014

Re, R., Pelegrini, N., Proteggente, A., Pannala, A., Yang, M., \& Rice-Evans, C. (1999). Antioxidant activity applying an improved ABTS radical cation decolorization assay. Free Radical Biology \& Medicine, 26, 1231-1237. https://doi.org/10.1016/S0891-5849(98)00315-3

Silva, M. C., Souza, V. B., Thomazini, M., Silva, E. R., Smaniotto, T., Carvalho, R. A., Genovese, M. I., \& Favaro-Trindade, C. S. (2014). Use of the jabuticaba (Myrciaria cauliflora) depulping residue to produce a natural pigment powder with functional properties. LWT - Food Science and Technology, 55, 203-209. https://doi.org/10.1016/j.lwt.2013.08.026

Sollohub, K., \& Cal, K. (2010). Spray drying technique: II. Current applications in pharmaceutical technology. Journal of Pharmaceutical Sciences, 99, 587-597. https://doi.org/10.1002/jps.21963

Thaipong, K., Boonprakob, U., Crosby, K., Cisneros-Zevallos, L., \& Byrne, D. H. (2006). Comparison of ABTS, DPPH, FRAP and ORAC assays for estimating antioxidant activity from guava fruits extracts. Journal of Food Composition and Analysis, 19, 669-675. https://doi.org/10.1016/j.jfca.2006.01.003

Tonon, R. V., Brabet, C., Pallet, D., Brat, P., \& Hubinger, M. D. (2009). Physicochemical and morphological characterisation of açai (Euterpe oleraceae Mart.) powder produced with different carrier agents. International Journal of Food Science \& Technology, 44, 1950-1958. https://doi.org/10.1111/j.1365-2621.2009.02012.x

Venkatachalam, R. N., Singh, K., \& Marar, T. (2012). Phytochemical screening and in vitro antioxidant activity of Psidium guajava. Free Radicals and Antioxidants, 2, 31-36. Retrieved from http://www.phcogfirst.com/sites/default/files/AX_2_1_7.pdf

Zulueta, A., Esteve, M. J., \& Frígola, A. (2009). ORAC and TEAC assays comparison to measure the antioxidant capacity of food products. Food Chemistry, 114, 310-316. https://doi.org/10.1016/j.foodchem.2008.09.033

\section{Copyrights}

Copyright for this article is retained by the author(s), with first publication rights granted to the journal.

This is an open-access article distributed under the terms and conditions of the Creative Commons Attribution license (http://creativecommons.org/licenses/by/4.0/). 